\title{
Milheto em substituição ao milho na dieta de novilhos confinados
}

\section{Millet as a replacement for corn in feedlot steers diets}

\author{
Alexey Heronville Gonçalves da Silva ${ }^{1 *}$; João Restle²; Regis Luis Missio ${ }^{3}$; \\ Ubirajara Oliveira Bilego ${ }^{4}$; Juliano José de Resende Fernandes ${ }^{5}$; \\ Pedro Leonardo de Paula Rezende ${ }^{1}$; Rodrigo Medeiros da Silva ${ }^{6}$; \\ Marcela Luzia Rodrigues Pereira ${ }^{1}$; Fabíola Alves Lino ${ }^{1}$
}

\section{Resumo}

Objetivou-se avaliar o desempenho bioeconômico de novilhos alimentados em confinamento com dietas com elevada proporção de concentrado $(80 \%)$ contendo diferentes níveis de grão de milheto moído em substituição ao grão de milho moído. Foram utilizados 89 novilhos não castrados, mestiços europeu-zebu, com peso médio inicial de $317,8 \pm 15,1 \mathrm{~kg}$ e idade média inicial de dois anos, distribuídos aleatoriamente em dietas com diferentes níveis de substituição do milho pelo milheto $(0,33,66$ e $100 \%)$. Os animais foram alojados em 16 baias coletivas. O delineamento experimental foi o inteiramente casualisado, com quatro tratamentos e quatro repetições (baias). O consumo de nutrientes, exceto fibra em detergente neutro e carboidratos não fibrosos, não diferiu $(\mathrm{P}>0,05)$ entre as dietas testadas. $\mathrm{O}$ ganho de peso médio diário, o peso corporal e o escore corporal final não foram alterados $(\mathrm{P}>0,05)$ pelo aumento do nível de milheto na dieta. A conversão alimentar aumentou em 0,0048 kg de matéria seca/ $\mathrm{kg}$ de ganho de peso para cada ponto percentual a mais de milheto na dieta. O custo total diminuiu linearmente $(\mathrm{P}<0,05)$ com o aumento do nível de milheto na dieta, reflexo da redução linear do custo com alimentação. Em função disso, o lucro da terminação de novilhos em confinamento aumentou $\mathrm{R} \$$ 0,675 a cada ponto percentual a mais de milheto em substituição ao milho da dieta. O milheto pode substituir totalmente o milho em dietas com elevada proporção de concentrado para bovinos confinados, possibilitando redução do custo de produção e aumento do lucro.

Palavras-chave: Custo, ganho de peso, integração lavoura-pecuária, receita bruta

\begin{abstract}
This study aimed to assess the bioeconomic performance of feedlot steers fed diets with high concentrate $(80 \%)$ containing different levels of grounded grain of millet as a replacement for grounded corn grain. We used 89 European-zebu crossbred bulls, with initial average weight of $317.8 \pm 15.1 \mathrm{~kg}$ and average initial age of two years, randomly assigned to diets with different levels of substitution of corn by millet $(0,33,66$ and $100 \%)$. The animals were allocated in 16 collective pens. The experimental design was a completely randomized design with four treatments and four replicates (pens). The nutrient intake,

\footnotetext{
${ }^{1}$ Discentes do Programa de Pós-Graduação em Ciência Animal, Universidade Federal de Goiás, UFG, Goiânia, GO. E-mail: alexheron@uol.com.br; padrozootec@hotmail.com; marcelaluziazoo@gmail.com; fabiola-lino@hotmail.com

${ }^{2}$ Bolsista PVNS CAPES, Fundação Universidade Federal do Tocantins, Araguaína, TO. E-mail: jorestle@terra.com.br

${ }^{3}$ Prof., Universidade Tecnológica Federal do Paraná, UTFPR, Pato Branco, PR. E-mail: regisluismissio@gmail.com

${ }^{4}$ Pesquisador, Cooperativa Agroindustrial dos Produtores Rurais do Sudoeste Goiano, Rio Verde, GO. E-mail: birabilego@, hotmail.com

5 Prof., Dept ${ }^{\circ}$ de Produção Animal, Escola de Veterinária e Zootecnia, Universidade Federal de Goiás, UFG, Goiânia, GO. E-mail: juliano@vet.ufg.br

6 Prof., Curso de Zootecnia, Campus São Luís de Montes Belos, Universidade Estadual de Goiás, UEG, Goiânia, GO. E-mail: rodrigo.medeiros@ueg.br

* Autor para correspondência
} 
except neutral detergent fiber and non-fiber carbohydrates, did not differ between the diets tested $(\mathrm{P}>0.05)$. The average daily weight gain, body weight and final body codition score were not affected $(\mathrm{P}>0.05)$ by increasing the level of millet in the diet. The feed conversion increased $0.0048 \mathrm{~kg}$ of dry matter $/ \mathrm{kg}$ of weight gain for each percentage point of millet in the diet. The total cost decreased linearly $(\mathrm{P}<0.05)$ with increasing the level of millet in the diet, reflecting the linear reduction in feed cost. As a result, the profit of finishing feedlot steers increased $\mathrm{R} \$ 0.675$ for each percentage point of millet in replacing corn. The millet can replace corn in diets with high concentrate for feedlot cattle, enabling reduction of production cost and increasing profits.

Key words: Cost, crop-livestock integration, gross income, weight gain

\section{Introdução}

A integração lavoura-pecuária e o confinamento são alternativas para o aumento do giro de capital e harmonização da renda dos produtores rurais durante o ano. Nesse sentido, a integração lavoura pecuária possibilita a maximização da utilização da terra pela produção de grãos provenientes de culturas anuais e a produção de bovinos no período de entressafra, com benefícios dos efeitos residuais dos fertilizantes das culturas anuais sobre o custo das pastagens, produção de subprodutos, assim como a utilização das culturas de sucessão para a produção de forragem e/ou grãos de menor custo para a alimentação animal. O confinamento, por sua vez, possibilita o aumento da taxa de desfrute, assim como a terminação de animais no período de entressafra, possibilitando maior remuneração. Além disso, essa estratégia pode ser beneficiada pela integração lavoura-pecuária, pois usufrui de forragens, grãos e/ou subprodutos com menor custo, notadamente quando utilizado de forma integrada a estes sistemas de produção e/ou em regiões próximas aquelas produtoras de grãos.

Dentre as culturas utilizadas em sucessão às culturas anuais, o milheto é uma das mais importantes para as regiões Centro-Oeste e Norte do país, sendo normalmente semeado após a cultura da soja, podendo ser utilizado para pastejo e produção de palhada para o plantio direto, para produção de grãos em substituição a cultura do milho (de maior risco na safrinha) e/ou para produção de silagem (BERGAMASCHINE et al., 2011). O milheto, apesar de apresentar grande potencial para a alimentação de ruminantes, está envolvido em um limitado número de estudos relacionados com a alimentação de bovinos de corte. Segundo Hill et al. (1996), espera-se que os bovinos alimentados com milheto e/ou misturas de grão milho com milheto tenham desempenho similar àqueles alimentados com dietas tradicionais, em que se utilizam grãos de milho ou de sorgo, ou ambos.

Deve-se destacar, no entanto, que a maioria dos estudos com milheto na dieta de bovinos utilizaram baixas proporções de concentrado (HILL; HANNA, 1990; RIBEIRO et al., 2004; BERGAMASCHINE et al., 2011). Em dietas com elevadas proporções de concentrado, o milheto pode beneficiar a digestão ruminal em função da melhoria do ambiente ruminal, como resultado do menor teor de carboidratos não fibrosos e amido das dietas, tal como proposto por Santos et al. (2001), Nussio et al. (2002) e Restle et al. (2004). Pode contribuir para isso, o fato do amido do milheto apresentar maior digestão no intestino delgado, como sugerido por Gonçalves et al. (2010). Esses aspectos podem refletir em aumento de consumo e desempenho animal, apesar de que, somente a manutenção do consumo de alimento e o desempenho animal já podem representar resultados favoráveis para a utilização do milheto na dieta, uma vez que seu custo é normalmente inferior ao milho.

O presente estudo objetivou avaliar o desempenho bioeconômico de novilhos alimentados em confinamento com dietas com elevada proporção de concentrado contendo diferentes níveis de milheto em substituição ao grão milho.

\section{Material e Métodos}

O trabalho foi desenvolvido entre agosto e novembro de 2010, nas instalações do Setor de 
Bovinocultura de Corte do Centro Tecnológico da Cooperativa Agroindustrial dos Produtores Rurais do Sudoeste Goiano, no município de Rio Verde/GO, localizado a $17^{\circ} 46^{\prime} 22^{\prime \prime}$ de latitude Sul e $51^{\circ} 02^{\prime} 86^{\prime \prime}$ de longitude Oeste e, 815 metros de altitude. Foram utilizados 45 tourinhos com predominância genotípica europeia (predominância de raças continentais) e 44 com predominância genotípica zebuína, com peso médio inicial de
317,8 e $320,7 \mathrm{~kg}$, respectivamente, e idade média inicial avaliada pela dentição de 21 meses. Os animais, oriundos de leilão comercial, foram classificados quanto à predominância genética por profissional treinado, levando em consideração suas características fenotípicas, sendo os animais de cada predominância genética distribuídos aleatoriamente nas dietas experimentais (Tabela 1).

Tabela 1. Ingredientes e composição química das dietas experimentais.

\begin{tabular}{llllll}
\hline \multirow{2}{*}{ Itens } & \multicolumn{3}{c}{ Nível de milheto na dieta } & Custo \\
\cline { 2 - 5 } & 0 & 33 & 66 & 100 & R \$/kg MS \\
\hline Silagem milho, \% MS & 20,00 & 20,02 & 20,00 & 20,02 & 0,16 \\
Milho, \% MS & 70,50 & 48,96 & 25,06 & 0,00 & 0,41 \\
Milheto, \% MS & 0,00 & 24,05 & 49,88 & 77,47 & 0,32 \\
Farelo de soja, \% MS & 8,02 & 5,49 & 3,61 & 1,19 & 0,67 \\
Uréia, \% MS & 0,62 & 0,63 & 0,60 & 0,49 & 1,06 \\
Núcleo mineral, \% MS & 0,86 & 0,85 & 0,85 & 0,83 & 1,12 \\
Custo, R\$/kg de MS & 0,36 & 0,33 & 0,30 & 0,27 & -- \\
Matéria seca, \% MN & 75,79 & 76,04 & 76,38 & 76,79 & -- \\
Matéria mineral, \% MS & 5,20 & 4,46 & 3,67 & 2,83 & -- \\
Proteína bruta, \% MS & 12,86 & 12,80 & 13,03 & 13,11 & -- \\
Extrato etéreo, \% MS & 3,38 & 3,68 & 3,99 & 4,34 & -- \\
Fibra em detergente neutro, \% MS & 19,81 & 21,82 & 24,06 & 26,44 & -- \\
Fibra em detergente ácido, \% MS & 9,88 & 10,34 & 10,84 & 11,39 & -- \\
Lignina, \% MS & 1,30 & 1,47 & 1,67 & 1,87 & -- \\
Nitrogênio insolúvel em detergente neutro, \% do N total & 0,06 & 0,13 & 0,19 & 0,26 & -- \\
Nitrogênio insolúvel em detergente ácido, \% do N total & 0,03 & 0,06 & 0,09 & 0,12 & - \\
Carboidratos totais, \% MS & 78,57 & 79,07 & 79,31 & 79,72 & -- \\
Carboidratos não fibrosos, \% MS & 58,76 & 57,25 & 55,24 & 53,28 & -- \\
Amido, \% MS & 58,10 & 55,79 & 53,25 & 50,63 & -- \\
Nutrientes digestíveis totais, \% MS & 75,53 & 74,69 & 73,75 & 72,76 & -- \\
Digestibilidade da matéria orgânica, \% & 90,24 & 89,19 & 88,09 & 86,99 & -- \\
\hline
\end{tabular}

$\mathrm{MN}=$ matéria natural; $\mathrm{MS}=$ matéria seca.

${ }^{1}$ Níveis de garantia (g/kg): Ca: 116; P: 61; S: 9; Na: 150; Mg: 0,69; Zn: 57,8 mg; Mn: 1; Cu: 1,88; Co: 0,16; I:0,16; Se: 0,02; monensina sódica: 2,4;

Fonte: Elaboração dos autores.

Os novilhos foram confinados em 16 baias coletivas $(10 \times 7,70 \mathrm{~m})$, quatro baias por tratamento, equipadas com bebedouros equipados com torneira boia e comedouros de concreto, sendo o piso a base de cascalho, com declive de 5\%. No início do experimento e a cada 28 dias os animais foram pesados individualmente após jejum de sólidos por 14-16 horas e avaliados quanto ao escore de condição corporal, considerando escala entre um (muito magro) e cinco (muito gordo). Os animais foram confinados por 96 dias, sendo o período experimental de 89 dias e sete dias para a adaptação dos animais às dietas, instalações e manejo de alimentação. 
As dietas foram formuladas considerando consumo de $2,4 \%$ do peso corporal para ganho de peso de $1,5 \mathrm{~kg} /$ dia. A ração foi fornecida em duas refeições diárias ( 8 h00 e 14h00), sendo o consumo de ração registrado diariamente e a oferta de alimentos mantida $10 \%$ acima do consumo voluntário. A composição química das dietas foi determinada em amostras de alimentos e sobras coletadas semanalmente, pré-secas em estufa com ventilação de ar forçado à $55^{\circ} \mathrm{C}$ por 72 horas e moídas em moinho tipo Willey, onde o tamanho de partícula foi de $1 \mathrm{~mm}$ de diâmetro. Os teores de matéria seca, matéria mineral (MM), extrato etéreo (EE) e proteína bruta $(\mathrm{PB})$ foram determinados segundo AOAC (1990). Os teores de nitrogênio insolúvel em detergente neutro (NIDN) e insolúvel em detergente ácido (NIDA) foram determinados segundo Licitra, Hernandez e Van Soest (1996). O teor de fibra em detergente neutro (FDN) foi determinado segundo Van Soest, Robertson e Lewis (1991). Os teores de fibra em detergente ácido e lignina foram determinados segundo Van Soest (1973). Os teores de carboidratos totais (CT) e carboidratos não fibrosos (CNF) foram determinados segundo Sniffen et al. (1992): $\mathrm{CT}=100-(\% \mathrm{~PB}+\% \mathrm{EE}+$ $\% \mathrm{MM})$ e $\mathrm{CNF}=\mathrm{CT}-\% \mathrm{FDN}$. O teor de nutrientes digestíveis totais (NDT) foi estimado segundo Cappelle et al. (2001): NDT $=83,79-(0,4171 *$ FDN). O teor de amido foi determinado segundo metodologia proposta por Silva e Queiroz (2002). A digestibilidade da matéria orgânica foi estimada a partir da composição química dos alimentos e dietas (WEISS; CONRAD; PIERRE, 1992).

A avaliação econômica foi realizada a partir das metodologias propostas por Kassai et al. (2000), Souza e Clemente (2004) e Pacheco et al. (2006). As dietas foram consideradas como projetos de investimento mutuamente excludentes, assumindose valores conhecidos para os itens que compõem os custos e receitas (Tabela 2) utilizados para o cálculo dos indicadores econômicos (Tabela 3), considerando os valores praticados no estado de Goiás no ano de 2010.

Tabela 2. Descrição dos itens de custos e receitas utilizados para cálculo dos indicadores econômicos, estimados por animal.

\begin{tabular}{|c|c|c|}
\hline Indicador & Unidade & Equação \\
\hline $\mathrm{CF}$ & $\mathrm{R} \$$ & $\begin{array}{l}=\text { depreciação de instalações, máquinas, implementos e equipamentos }+ \text { oportunidade de } \\
\text { instalações, máquinas, implementos e equipamentos }+ \text { oportunidade da terra }\end{array}$ \\
\hline $\mathrm{CV}$ & $\mathrm{R} \$$ & $\begin{array}{l}=\text { compra do animal magro }+ \text { controle sanitário }+ \text { alimentação }+ \text { mão-de-obra }+ \text { assistência } \\
\text { técnica }+ \text { outras despesas }+ \text { oportunidade do capital investido }\end{array}$ \\
\hline $\mathrm{COE}$ & $\mathrm{R} \$$ & $\begin{array}{l}=\text { compra do animal magro }+ \text { controle sanitário }+ \text { alimentação }+ \text { mão-de-obra }+ \text { assistência } \\
\text { técnica }+ \text { outras despesas }\end{array}$ \\
\hline COT & $\mathrm{R} \$$ & $\begin{array}{l}=\text { compra do animal magro }+ \text { controle sanitário }+ \text { alimentação }+ \text { mão-de-obra }+ \\
\text { assistência técnica }+ \text { outras despesas }+ \text { depreciação (instalações, máquinas, implementos } \\
\text { e equipamentos) }\end{array}$ \\
\hline $\mathrm{CT}$ & $\mathrm{R} \$$ & $=$ custo fixo + custo variável \\
\hline $\mathrm{C} / \mathrm{GMD}$ & $\mathrm{R} \$ / \mathrm{kg}$ & $=($ custo total - custo do animal magro $) /$ ganho de peso total \\
\hline c/@ & R\$/@ & $=$ custo total $/$ peso de carcaça quente $/ 15$ \\
\hline Receita & $\mathrm{R} \$$ & $\begin{array}{l}=((\text { peso corporal final* } * \text { rendimento de carcaça quente médio/100) }) / 15) * \text { preço da arroba } \\
\text { do boi gordo }\end{array}$ \\
\hline
\end{tabular}

$\mathrm{CF}=$ custo fixo; $\mathrm{CV}=$ custo variável $; \mathrm{COE}=$ custo operacional efetivo; $\mathrm{COT}=$ custo operacional total; $\mathrm{CT}=$ custo total; $\mathrm{C} / \mathrm{GMD}$ = custo/ganho de peso médio diário; $\mathrm{C} / @=$ custo/@ de carcaça.

Fonte: Elaboração dos autores. 
Tabela 3. Descrição dos indicadores econômicos, estimados por animal.

\begin{tabular}{|c|c|c|}
\hline Indicador & Unidade & Equação \\
\hline Margem bruta & $\mathrm{R} \$$ & $=$ receita $-\mathrm{COE}$ \\
\hline Margem líquida & $\mathrm{R} \$$ & $=$ receita $-\mathrm{COT}$ \\
\hline Lucro & $\mathrm{R} \$$ & $=$ receita - custo total \\
\hline $\begin{array}{l}\text { Valor presente líquido } \\
\text { (VPL) }\end{array}$ & $\mathrm{R} \$$ & $\sum_{=i=1}^{n} \frac{\text { valores }_{i}}{(1+T M A)^{i}}$, onde $\mathrm{n}=$ número de fluxos de caixa e $T M A=$ taxa mínima \\
\hline $\begin{array}{l}\text { Índice benefício custo } \\
\text { (IBC) }\end{array}$ & & $\begin{array}{l}\text { = Valor presente dos fluxos de caixa positivos/valor presente dos fluxos de } \\
\text { caixa negativos }\end{array}$ \\
\hline $\begin{array}{l}\text { Retorno adicional } \\
\text { sobre o investimento } \\
\text { (ROIA) }\end{array}$ & $\%$ a.m. & 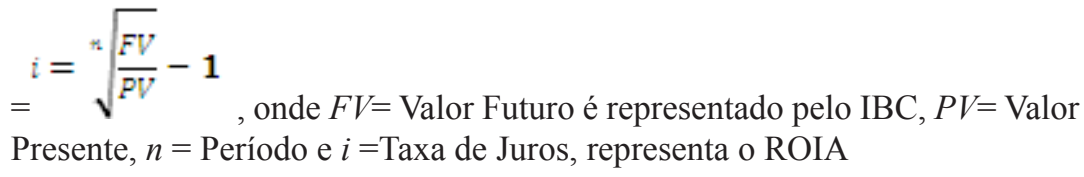 \\
\hline $\begin{array}{l}\text { Taxa interna de } \\
\text { retorno (TIR) }\end{array}$ & $\%$ a.m. & $\begin{array}{l}-I+\sum_{t=1}^{n} \frac{F C_{t}}{(1+T I R)^{t}} \text {, onde: } I=\text { investimento de capital na data zero, } F C_{t}= \\
\text { retorno na data } t \text { do fluxo de caixa e } n=\text { prazo de análise do projeto }\end{array}$ \\
\hline
\end{tabular}

Fonte: Elaboração dos autores.

O custo com depreciação foi determinado pelo método linear, considerando o valor de sucata de $10 \%$, em que as instalações, máquinas, implementos e equipamentos utilizados são listados na Tabela 4 . O custo de oportunidade de instalações, máquinas, implementos e equipamentos foi determinado para o período de confinamento (89 dias), tendo considerando como taxa de atratividade mínima o rendimento da poupança $(0,5 \%$ a.m. $)$. $O$ custo de oportunidade da terra foi determinado considerando a equação: [área (ha) necessária para produção da quantidade de volumoso consumida por animal * custo por ha/dia] * período para produção, confecção e utilização do volumo (120 dias). O custo por ha/dia foi determinado considerando que o arrendamento de 1 ha $=10$ sacos de soja, ou seja, $\mathrm{R} \$ 308,1 / \mathrm{ha} /$ ano, obtendo-se o custo de R\$ 0,84/ha/dia, sendo o preço médio da saca da soja de $\mathrm{R} \$ 30,81$. Para fins de comparação futura de resultados, considerou-se $\mathrm{US} \$=\mathrm{R} \$ 1,74$ e IGPM $-\mathrm{FNP} / \mathrm{FGV}$ (índice geral de preços de mercado FNP/Fundação Getúlio Vargas) = valor em $\mathrm{R} \$ / 0,72$ (janeiro $1980=100$ ), multiplicando-se o valor do IGPM - FNP/FGV obtido pelo IGPM- FNP/FGV de qualquer mês e ano (comparação dos valores em R\$).

$\mathrm{O}$ custo de aquisição dos animais (CAA) foi determinado considerando o custo da arroba do boi magro (agosto/2010) de $\mathrm{R} \$ 88,00$, rendimento de carcaça de $50 \%$, corretagem sobre o preço de comercialização de $5 \%$, em que: $\mathrm{CAA}=$ [peso corporal inicial*rendimento de carcaça + ((peso corporal inicial*rendimento de carcaça $)^{*}$ taxa de corretagem))]. O preço de comercialização da arroba do boi pronto para abate (novembro/2010) foi de R $\$ 108$. O custo com manejo sanitário levou em consideração o valor médio dos custos com esse item ao longo do período de confinamento. $\mathrm{O}$ custo com alimentação foi determinado considerando o consumo de alimento e relação volumoso: concentrado da dieta. O custo do volumoso foi determinado segundo Pacheco et al. (2006), considerando produção média de 40 t/ha de matéria verde de silagem. 
Tabela 4. Descrição dos itens considerados para o cálculo de depreciação.

\begin{tabular}{lcc}
\hline Itens & Vida útil (anos) & Custo (R\$) \\
\hline Confinamento comercial para 500 animais & 20 & $50.000,00$ \\
Centro de manejo com balança mecânica & 20 & $70.000,00$ \\
Galpão para armazenamento de ração & 20 & $30.000,00$ \\
Misturador horizontal & 20 & $4.500,00$ \\
Triturador de grãos & 20 & $3.500,00$ \\
Trator Massey Ferguson/Modelo 275/1994 & 15 & $70.000,00$ \\
Vagão forrageiro & 10 & $15.000,00$ \\
Colhedoura de forragem & 15 & $30.000,00$ \\
Equipamentos em geral & 2 & $3.000,00$ \\
\hline
\end{tabular}

Fonte: Elaboração dos autores.

O custo com mão-de-obra foi de dois salários mínimos mensais( $\mathrm{R} \$ 1020,00)$ mais encargos sociais, considerando a necessidade de um homem para 300 bois confinados, correspondente com as atividades de preparo e fornecimento da alimentação, limpeza das instalações e manejo dos animais. O custo com assistência técnica foi de quatro salários mínimos mensais (R $\$ 2040,00)$, considerando seis horas diárias para cada 1.000 animais em confinamento. O custo com outras despesas (combustível, energia elétrica, frete, impostos e alimentação da mãode-obra) foi determinado considerando um valor fixo $(2,5 \%)$ em relação ao somatório dos custos com aquisição de animais, alimentação, mão-deobra, controle sanitário e assistência técnica. O custo de oportunidade do capital investido (COCI) foi determinado pela equação: COCI $=$ [custo operacional efetivo*taxa de juros média diária da poupança $\left(1+0,5^{(1 / 30)-1}\right) *$ período de confinamento.

O delineamento experimental utilizado foi o inteiramente casualisado, com quatro tratamentos e quatro repetições (baias). O número de animais foi de 21, 21, 23 e 24 para as dietas com 0, 33, 66 e $100 \%$ de milheto na dieta, respectivamente. Os dados foram submetidos a análise de normalidade e homogeneidade de variâncias e, quando necessário esses foram transformados utilizando-se a função $\log ^{2}$. Depois de satisfeitas as pressuposições de normalidade e homogeneidade de variâncias, os dados foram submetidos à análise de variância, regressão polinomial e teste para a falta de ajuste das equações de regressão (lack-of-fit), a $5 \%$ de probabilidade, utilizando-se o PROC REG do SAS (Statistical Analysis System, versão 9.2).

\section{Resultados e Discussão}

O consumo de nutrientes, exceto fibra em detergente neutro e carboidratos não fibrosos, não foi alterado $(\mathrm{P}>0,05)$ pelo aumento do milheto em substituição ao milho na dieta (Tabela 5), concordando com Ribeiro et al. (2004) e Gonçalves et al. (2010). Por outro lado, Gelaye et al. (1997) e Bergamaschine et al. (2011) verificaram redução do consumo de matéria seca em cabritas e bezerros pelo aumento do milheto em substituição ao milho na dieta, respectivamente. Esses autores atribuíram tais resultados à menor palatabilidade do milheto, uma vez que não verificaram redução do consumo de alimento nas categorias análogas com estágio de desenvolvimento corporal mais avançado (cabras e novilhos, respectivamente). Neste estudo, o similar consumo de matéria seca demonstrou que não há diferença quanto à aceitabilidade entre os grãos estudados por novilhos, concordando com os resultados de Ribeiro et al. (2004) e Gonçalves et al. (2010), os quais testaram níveis de milheto em dietas para vacas leiteiras e novilhos, respectivamente. 
Tabela 5. Variáveis referentes ao consumo de nutrientes e desempenho de bovinos alimentados com dietas contendo diferentes níveis de milheto em substituição ao milho da dieta.

\begin{tabular}{|c|c|c|c|c|c|c|c|}
\hline \multirow{2}{*}{ Variáveis } & \multicolumn{4}{|c|}{ Milheto na dieta (\%) } & \multirow{2}{*}{$\mathrm{CV}$} & \multicolumn{2}{|c|}{ ER } \\
\hline & 0 & 33 & 66 & 100 & & $\mathrm{~L}$ & $\mathrm{Q}$ \\
\hline Consumo de matéria seca, $\mathrm{kg} / \mathrm{dia}$ & 8,94 & 8,49 & 9,25 & 8,73 & 11,94 & 0,949 & 0,934 \\
\hline Consumo de matéria seca, \% PC & 2,25 & 2,17 & 2,30 & 2,23 & 6,92 & 0,953 & 0,925 \\
\hline Consumo de proteína bruta, $\mathrm{kg} / \mathrm{dia}$ & 1,26 & 1,17 & 1,34 & 1,26 & 11,94 & 0,877 & 0,819 \\
\hline Consumo de proteína bruta, $\%$ PC & 0,32 & 0,31 & 0,33 & 0,31 & 7,19 & 0,926 & 0,500 \\
\hline Consumo de fibra em detergente neutro, $\mathrm{kg} / \mathrm{dia}$ & 0,96 & 1.05 & 1,39 & 1,40 & 14,99 & 0,008 & 0,455 \\
\hline Consumo de fibra em detergente neutro, $\%$ PC & 0,24 & 0,27 & 0,35 & 0,36 & 10,11 & $<0,000$ & 0,308 \\
\hline Consumo de carboidratos não fibrosos, $\mathrm{kg} / \mathrm{dia}$ & 6,26 & 5,89 & 6,19 & 5,74 & 11,81 & 0,230 & 0,702 \\
\hline Consumo de carboidratos não fibrosos, $\%$ PC & 1,58 & 1,54 & 1,53 & 1,44 & 7,06 & 0,037 & 0,516 \\
\hline Consumo de nutrientes digestíveis totais, $\mathrm{kg} / \mathrm{dia}$ & 7,03 & 6,67 & 7,17 & 6,74 & 11,92 & 0,809 & 0,954 \\
\hline Consumo de nutrientes digestíveis totais, $\%$ PC & 1,78 & 1,71 & 1,79 & 1,73 & 6,92 & 0,563 & 0,927 \\
\hline Peso corporal inicial, $\mathrm{kg}$ & 316,9 & 324,4 & 324,2 & 323,9 & -- & -- & -- \\
\hline Peso corporal final, $\mathrm{kg}$ & 472,7 & 465,0 & 480,0 & 462,7 & 7,28 & 0,836 & 0,777 \\
\hline Ganho de peso médio diário, $\mathrm{kg}$ & 1,75 & 1,58 & 1,75 & 1,56 & 15,18 & 0,487 & 0,932 \\
\hline Ganho de peso total, $\mathrm{kg}$ & 155,5 & 141,0 & 156,0 & 139,2 & 15,18 & 0,501 & 0,920 \\
\hline Escore corporal final, pontos & 3,78 & 3,70 & 3,69 & 3,66 & 2,42 & 0,085 & 0,601 \\
\hline Ganho em escore corporal, pontos & 0,94 & 0,71 & 0,77 & 0,79 & 17,74 & 0,245 & 0,079 \\
\hline Conversão alimentar, $\mathrm{kg} \mathrm{MS} / \mathrm{kg}$ de gan & 5,11 & 5,38 & 5,31 & 5,66 & 5,41 & 0,029 & 0,774 \\
\hline Conversão energética, $\mathrm{kg}$ NDT $/ \mathrm{kg}$ de ganho de PC & 4,02 & 4,22 & 4,10 & 4,32 & 5,34 & 0,098 & 0,758 \\
\hline
\end{tabular}

Consumo de fibra em detergente neutro $(\mathrm{CFDN}), \mathrm{kg} / \mathrm{dia}=0,97+0,046 \mathrm{x}, \mathrm{R}^{2}=0,55, \mathrm{DR}=0,324 ; \mathrm{CFDN}, \% \mathrm{PC}=0,246+0,0012 \mathrm{x}$, $\mathrm{R}^{2}=0,71, \mathrm{DR}=0,246$; Consumo de carboidratos não fibrosos, $\% \mathrm{PC}=1,59-0,0015 \mathrm{x}, \mathrm{R}^{2}=0,30$, $\mathrm{DR}=0,269$; Conversão alimentar $=3,031+0,0048 \mathrm{x}, \mathrm{R}^{2}=0,50, \mathrm{DR}=0,506 ; \mathrm{x}=\%$ de milheto na dieta; $\mathrm{DR}=$ probabilidade para os desvios da regressão (ajuste da regressão); $\mathrm{CV}=$ coeficiente de variação; $\mathrm{ER}=$ equações de regressão; $\mathrm{L}=$ linear; $\mathrm{Q}=$ quadrática; $\mathrm{MS}=$ matéria seca; $\mathrm{NDT}=$ nutrientes digestíveis totais; $\mathrm{PC}=$ peso corporal.

Fonte: Elaboração dos autores.

O consumo de fibra em detergente neutro aumentou e o consumo de carboidratos não fibrosos expresso em percentagem do peso corporal diminuiu linearmente $(\mathrm{P}<0,05)$ com o avanço do teor de milheto na dieta (Tabela 5). Esses resultados refletiram as diferenças na composição química do milheto em relação ao milho (Tabela 6), onde o milheto apresentou maior teor de fibra em detergente neutro $(46,1 \%)$ e menor teor de carboidratos não fibrosos $(14,7 \%)$ que o milho, resultados coerentes com a composição destes grãos (VALADARES FILHO et al., 2006).

Embora tenha ocorrido redução significativa do consumo de carboidratos não fibrosos, não foram detectadas evidencias de que o menor teor de amido das dietas com grão de milheto (Tabela 6) tenha proporcionado melhores condições do ambiente ruminal a ponto de beneficiar a digestibilidade ruminal, como proposto por Santos et al. (2001), Nussio et al. (2002) e Restle et al. (2004). Por outro lado, evidenciou-se que a digestibilidade da matéria orgânica, estimada a partir da composição química das dietas, diminuiu com o avanço do teor de milheto em substituição ao milho (Tabela 1), fato associado ao incremento do teor de nitrogênio ligado a fibra indigestível da dieta. Vale lembrar que essa estimativa da digestibilidade não considera as interações relacionadas com a degradação dos alimentos no ambiente ruminal, podendo representar menor precisão em relação às técnicas que simulam a degradação ruminal e/ou ao método in vivo. É importante ressaltar ainda que os resultados 
apresentados na literatura não são consistentes quanto ao padrão de resposta da digestibilidade de dietas contendo níveis crescentes de milheto em substituição ao milho (HILL et al., 1996; GONÇALVES et al., 2010; BERGAMASCHINE et al., 2011), o que dificulta a caracterização de causa e efeito para os resultados obtidos.

Tabela 6. Composição química dos ingredientes

\begin{tabular}{lllll}
\hline \multicolumn{1}{c}{ Itens } & $\begin{array}{l}\text { Silagem } \\
\text { milho }\end{array}$ & Milho & Milheto & $\begin{array}{l}\text { Farelo } \\
\text { de soja }\end{array}$ \\
\hline Matéria seca, \% MN & 34,55 & 87,2 & 88,63 & 90,5 \\
Matéria mineral, \% MS & 3,94 & 5,40 & 2,43 & 6,47 \\
Proteína bruta, \% MS & 7,80 & 10,44 & 14,01 & 46,93 \\
Extrato etéreo, \% MS & 3,24 & 3,55 & 4,72 & 2,80 \\
Fibra em detergente neutro, \% MS & 51,2 & 11,09 & 20,56 & 21,85 \\
Fibra em detergente ácido, \% MS & 33,1 & 3,85 & 6,04 & 6,76 \\
Lignina, \% MS & 4,16 & 0,51 & 1,32 & 1,33 \\
Nitrogênio insolúvel em detergente neutro, \% do N total & 0,12 & 0,11 & 0,68 & 0,3 \\
Nitrogênio insolúvel em detergente ácido, \% do N total & 0,05 & 0,02 & 0,14 & 0,13 \\
Carboidratos totais, \% MS & 85,02 & 84,92 & 79,84 & 43,8 \\
Carboidratos não fibrosos, \% MS & 56,75 & 74,93 & 63,9 & 24,13 \\
Amido, \% MS & 17,56 & 70,76 & 59,92 & 58,69 \\
Nutrientes digestíveis totais, \% MS & 70,37 & 81,84 & 75,21 & 74,68 \\
Digestibilidade da matéria orgânica, \% MS & 81,46 & 93,11 & 88,23 & 82,41 \\
\hline
\end{tabular}

$\mathrm{MN}=$ matéria natural; $\mathrm{MS}=$ matéria seca; $\mathrm{N}=$ nitrogênio.

Fonte: Elaboração dos autores.

O ganho de peso médio diário e o peso corporal final não foram alterados $(\mathrm{P}<0,05)$ pelo nível de substituição do milho pelo milheto na dieta (Tabela 5), concordando com os resultados de Hill et al. (1996), Gonçalves et al. (2010) e Bergamaschine et al. (2011). Por outro lado, Hill e Hanna (1990) verificaram menor ganho de peso $(1,16 \mathrm{~kg} / \mathrm{dia}) \mathrm{em}$ novilhas de corte alimentadas com milheto, em relação àquelas que receberam milho e farelo de soja $(1,37 \mathrm{~kg} / \mathrm{dia})$, fato atribuído ao menor consumo de ração. Destaca-se que os resultados obtidos no presente estudo refletiram os similares teores de energia e proteína das dietas (Tabela 1), bem como o semelhante consumo de matéria seca ocorrido entre estas, evidenciando a viabilidade biológica da utilização do milheto na formulação de dietas para bovinos confinados, tal como proposto por Hill et al. (1996). É válido ressaltar que o ganho de peso médio diário verificado neste estudo foi similar ao verificado $(1,76 \mathrm{~kg} / \mathrm{dia})$ no estudo de Hill et al. (1996), os quais utilizaram novilhos mestiços Angus x Hereford alimentados com dietas com $85 \%$ de concentrado, contendo 50\% de milheto em substituição ao grão milho. Por outro lado, o ganho de peso médio diário verificado nas diferentes dietas deste estudo superou os valores de 0,$97 ; 1,04 ; 0,94$; 1,07 e 1,07 kg/dia obtidos nas dietas com 0, 23, 49,80 e $96 \%$ de milheto em substituição ao milho do estudo de Bergamaschine et al. (2011), o que se deve à categoria animal (machos castrados) e a menor proporção de concentrado $(50 \%)$ utilizada por esses autores.

$\mathrm{O}$ escore de condição corporal, bem como o ganho em escore corporal não foi alterado $(\mathrm{P}>0,05)$ pelo aumento do nível de substituição do milho pelo milheto (Tabela 5). O escore de condição corporal final é um indicativo do acabamento dos animais, sendo reflexo do ganho de peso e da composição do ganho para um mesmo genótipo e/ou categoria. 
Nesse sentido, maiores taxas de crescimento determinam maiores taxas de deposição de gordura corporal (NRC, 1996), fato verificado neste estudo pela correlação significativa $(\mathrm{r}=0,77)$ do escore de condição corporal com o ganho de peso médio diário. Todavia, essa teoria não é unânime para animais terminados em confinamento, onde o tempo de alimentação é determinante sobre o acúmulo de gordura corporal. Nesse sentido, animais submetidos a um maior período de alimentação podem apresentar maior acúmulo de gordura corporal (PACHECO et al., 2006; MISSIO et al., 2009), como reflexo da compensação de menores taxas de depósito de gordura por um período de tempo mais prolongado até o abate, em relação aos animais que atingiram peso de abate mais cedo em função de maiores taxas de ganho de peso. Vale destacar que o período de confinamento, no presente estudo, foi semelhante entre as dietas experimentais, justificando os resultados obtidos.

A conversão alimentar apresentou ajuste $(\mathrm{P}<0,05)$ à equação de regressão linear, aumentando em média $0,0048 \mathrm{~kg}$ de matéria seca $/ \mathrm{kg}$ de ganho de peso para cada ponto percentual a mais de milheto em substituição ao milho na dieta (Tabela 5), reflexo da menor densidade energética do milheto e redução da digestibilidade com o avanço do teor de milheto nas dietas (Tabela 1 e 6). Estes resultados indicam que a manutenção do ganho de peso esteve associada com o aumento do consumo de alimento no intuito de atender a demanda energética pelos animais alimentados com maior teor de milheto na dieta, embora tal fato não tenha se manifestado de forma significativa pelo consumo de matéria seca e conversão de energia em ganho de peso corporal (Tabela 5). Os resultados obtidos quanto à conversão alimentar foram similares aos verificados por Hill e Hanna (1990), com substituição total e Hill et al. (1996), com substituição parcial (67\%) do milho e total do farelo de soja pelo milheto na dieta de novilhas ou de 50\% milho na dieta de novilhos. Vale destacar que estes autores verificaram pior conversão alimentar para as dietas com milheto, fato atribuído pelos autores à menor densidade energética destas dietas. Embora Hill et al. (1996) tenham verificado alteração da conversão alimentar, o desempenho animal não foi alterado pela utilização do milheto na dieta, o que corrobora com o presente estudo. Outros autores (BERGAMASCHINE et al., 2011) verificaram que a conversão alimentar não foi alterada pela substituição do milho pelo milheto na dieta de novilhos confinados. Nesse estudo percebese que a utilização do milheto não determinou grande impacto sobre a densidade energética das dietas, bem como sobre a digestibilidade e consumo de alimento.

As situações levantadas reportam para a possibilidade de variações inerentes à composição química do milheto, o que pode estar associado aos cuidados com os tratos culturais, de colheita e conservação deste grão, bem como relacionado com as diferentes aptidões das cultivares. É importante salientar ainda que os valores referentes à conversão alimentar foram condizentes com a categoria animal utilizada, em que o valor médio foi de $5,36 \mathrm{~kg}$ de matéria seca/kg de ganho de peso. Esse valor foi inferior aos resultados $(9,55 \mathrm{~kg}$ de matéria seca/ $\mathrm{kg}$ de ganho de peso) obtidos por Bergamaschine et al. (2011) com novilhos Guzerá de 24-30 meses de idade, resultado da categoria animal e teor de concentrado utilizado (50\%) por esses autores. Por outro lado, a conversão alimentar obtida se aproximou dos resultados obtidos por Hill et al. (1996), os quais verificaram valores de 7,7 kg de matéria seca/kg de ganho de peso em tourinhos mestiços Angus x Hereford de 16-18 meses de idade alimentados com milheto na dieta.

Tão importante quanto avaliar a eficiência biológica da utilização do milheto na dieta de bovinos, é o impacto econômico dessa alternativa alimentar sobre o sistema de produção (Tabelas 7, 8 e 9). Nesse sentido, verificou-se que os custos fixos (Tabela 7), compostos pelo custo de oportunidade da terra, custo com depreciações e com os juros sobre o capital empatado, não foram alterados $(\mathrm{P}>0,05)$ pelo aumento da proporção de milheto na dieta. 
Estes resultados foram reflexos do similar consumo de alimento, o que determinou que a área necessária para a produção de silagem foi semelhante entre tratamentos. Além disso, contribuíram para estes resultados o fato das dietas apresentarem semelhante proporção de volumoso, bem como pelo similar tempo de confinamento necessário para conduzir os animais até o abate. Vale destacar que mesmo que nenhum animal fosse confinado, o custo com depreciação permaneceria onerando o sistema de produção até a total depreciação das instalações e equipamentos. Rodrigues Filho et al. (2002) demonstraram que o aumento do número de bezerros confinados de 24 para 48 , considerando o período de confinamento para a mesma estrutura, reduziria o custo fixo médio por animal em, no mínimo, 50\%. Tal fato segundo esses autores indica que a escala de produção é importante parâmetro a ser considerado na eficiência econômica deste sistema de produção, não somente pela redução destes custos, em decorrência do aumento da produção, mas também pelo reflexo direto no preço de aquisição dos insumos.

Tabela 7. Variáveis referentes aos componentes do custo de produção e receita da terminação de bovinos alimentados com dietas contendo milheto em substituição ao milho em confinamento.

\begin{tabular}{|c|c|c|c|c|c|c|c|}
\hline \multirow{2}{*}{ Itens (R\$/animal) } & \multicolumn{4}{|c|}{ Milheto (\%) } & \multirow{2}{*}{$\mathrm{CV}$} & \multicolumn{2}{|c|}{ ER } \\
\hline & 0 & 33 & 66 & 100 & & $\mathrm{~L}$ & $\mathrm{Q}$ \\
\hline Custos fixos & 14,19 & 14,13 & 14,23 & 14,16 & 0,94 & 0,956 & 0,939 \\
\hline Oportunidade da terra & 1,18 & 1,12 & 1,22 & 1,15 & 11,60 & 0,948 & 0,948 \\
\hline Depreciações & 12,85 & 12,85 & 12,85 & 12,85 & -- & -- & -- \\
\hline Oportunidade capital depreciado & 0,16 & 0,16 & 0,16 & 0,16 & -- & -- & -- \\
\hline Custos variáveis ${ }^{1}$ & 1368,39 & 1352,73 & 1347,55 & 1307,93 & 5,68 & 0,023 & 0,763 \\
\hline Aquisição de animais & 976,81 & 997,57 & 997,55 & 995,40 & 4,66 & 0,576 & 0,937 \\
\hline Volumoso & 25,79 & 24,51 & 26,70 & 25,21 & 11,44 & 0,945 & 0,934 \\
\hline Concentrado $^{2}$ & 285,89 & 251,31 & 244,16 & 209,60 & 11,47 & 0,002 & 0,987 \\
\hline Alimentação ${ }^{3}$ & 311,68 & 275,82 & 270,86 & 234,81 & 11,46 & 0,003 & 0,994 \\
\hline Mão-de-obra & 14,60 & 14,60 & 14,60 & 14,60 & -- & -- & -- \\
\hline Assistência técnica & 9,26 & 9,26 & 9,26 & 9,26 & -- & -- & -- \\
\hline Controle sanitário & 6,69 & 6,69 & 6,69 & 6,69 & -- & -- & -- \\
\hline Outros & 32,98 & 32,60 & 32,47 & 31,52 & 5,70 & 0,226 & 0,763 \\
\hline Oportunidade capital investido & 16,37 & 16,19 & 16,12 & 15,65 & 5,70 & 0,223 & 0,761 \\
\hline Custo total ${ }^{4}$ & 1511,15 & 1492,79 & 1487,96 & 1448,28 & 5,64 & 0,007 & 0,765 \\
\hline $\mathrm{COE}^{5}$ & 1352,02 & 1336,54 & 1331,43 & 1292,28 & 5,68 & $<0,001$ & 0,763 \\
\hline $\mathrm{COT}^{6}$ & 1368,39 & 1352,73 & 1347,55 & 1307,93 & 4,90 & $<0,001$ & 0,763 \\
\hline Rendimento carcaça quente, $\%$ & 53,80 & 53,95 & 53,28 & 54,99 & -- & -- & -- \\
\hline Receita & 1831,05 & 1806,25 & 1841,36 & 1831,96 & 7,28 & 0,836 & 0,777 \\
\hline Custo/kg de ganho de peso ${ }^{7}$ & 2,61 & 2,62 & 2,33 & 2,35 & 6,52 & 0,020 & 0,884 \\
\hline Custo/arroba de carcaça ${ }^{8}$ & 81,55 & 81,73 & 79,87 & 77,94 & 2,31 & 0,009 & 0,822 \\
\hline
\end{tabular}

${ }^{1} \mathrm{Y}=1304,649-0,5781 \mathrm{x}, \mathrm{R}^{2}=0,92, \mathrm{DR}=0,720 ;{ }^{2} \mathrm{Y}=283,224-0,709 \mathrm{x}, \mathrm{R}^{2}=0,55, \mathrm{DR}=0,703 ;{ }^{3} \mathrm{Y}=308,511-0,708 \mathrm{x}, \mathrm{R}^{2}=0,50$, $\mathrm{DR}=0,689 ;{ }^{4} \mathrm{Y}=-161,48-0,833 \mathrm{x}+4,5947 \mathrm{~A}, \mathrm{R}^{2}=0,98, \mathrm{DR}=0,655 ;{ }^{5} \mathrm{Y}=-171,34-0,822 \mathrm{x}+4,78 \mathrm{~A}, \mathrm{R}^{2}=0,92, \mathrm{DR}=0,920 ;{ }^{6} \mathrm{Y}=$ $-173,446-0,832 \mathrm{x}+4,838 \mathrm{~A}, \mathrm{R}^{2}=0,92, \mathrm{DR}=0,920 ;{ }^{7} \mathrm{Y}, \mathrm{R} \$=2,65-0,00294 \mathrm{x}, \mathrm{R}^{2}=0,35, \mathrm{DR}=0,104 ;{ }^{8} \mathrm{Y}, \mathrm{R} \$=82,22-0,037 \mathrm{x}, \mathrm{R}^{2}$ $=0,43, \mathrm{DR}=0,111 ; \mathrm{x}=\%$ de milheto na dieta; $\mathrm{A}=$ custo de aquisição dos animais; $\mathrm{DR}=$ probabilidade para os desvios da regressão (ajuste da regressão); $\mathrm{COE}=$ custo operacional efetivo; $\mathrm{COT}=$ custo operacional total.

Fonte: Elaboração dos autores. 
O somatório dos custos variáveis, bem como o custo operacional efetivo, o custo operacional total e o custo total diminuíram linearmente $(\mathrm{P}<0,05)$ pelo aumento do nível de substituição do milho pelo milheto na dieta, refletindo a redução linear do custo com concentrado e, consequentemente, do custo com alimentação (Tabela 7). Estes resultados foram atribuídos ao menor preço de mercado praticado para o milheto frente ao milho, o qual foi $22,2 \%$ menor (Tabela 1). Faturi et al. (2003) avaliando o grão de aveia preta em substituição ao grão de sorgo e Ezequiel et al. (2006) avaliando o farelo de gérmen milho, a casca do grão de soja ou a polpa de citrus em substituição ao grão milho na dieta de bovinos confinados, verificaram redução do custo com alimentação, fato também associado ao menor custo dos alimentos que substituíram o milho ou sorgo na dieta. Vale destacar que o custo com alimentação, especialmente aquele referente à fração concentrada da dieta, é um dos principais componentes dos custos em confinamento (PACHECO et al., 2006; RESTLE et al., 2007; MISSIO et al., 2009), tendo, dessa forma, grande importância sobre a viabilidade econômica dessa atividade.

Os demais custos variáveis não foram alterados pelo aumento da quantidade de milheto em substituição ao milho na dieta (Tabela 7), o que de certa forma é justificável, uma vez que a substituição de um alimento por outro de menor custo apresenta maior impacto sobre o custo com alimentação, especialmente sobre a fração da dieta na qual se substitui o alimento de interesse (fração volumosa ou concentrada). Contribuíram para estes resultados o fato dos animais apresentarem similar consumo de alimento e a proporção de volumoso das dietas ter sido a mesma, o que determinou que o custo com volumoso e a logística de alimentação não fossem alterados pelos tratamentos. Deve-se destacar que a maioria dos custos variáveis demandados em cada tratamento foram similares devido ao semelhante tempo de confinamento. Tais pressuposições foram concordantes com as verificações de Missio et al. (2009), os quais verificaram que o período de confinamento, determinado pela maior ou menor proporção de concentrado da dieta, foi um dos principais fatores responsáveis pelas alterações dos custos de produção, fato também verificado por Rodrigues Filho et al. (2002).

A receita não foi alterada significativamente pelas dietas experimentais (Tabela 7), fato associado ao semelhante desenvolvimento corporal proporcionado pelas dietas e pelo semelhante preço de comercialização. É válido destacar que não foi verificada, durante o abate dos animais, a ocorrência de alterações qualitativas nas carcaças que pudessem determinar diferenciação do preço de comercialização. Por outro lado, considerando a manutenção da receita e a redução do custo total pelo aumento do nível de substituição do milho pelo de milheto na dieta, verificou-se redução linear do custo/kg de ganho de peso e do custo/@ de carcaça. Apesar dessa redução, o custo da arroba produzida foi superior e/ou muito próximo do preço de comercialização do boi pronto para abate entre os meses de janeiro e junho de 2010 (ANUALPEC, 2011). Este aspecto remete para a necessidade do planejamento do confinamento no intuito de obterem-se animais prontos para o abate em período de maior preço de comercialização, bem como pela necessidade na redução dos custos de produção para a obtenção de lucratividade favorável.

É importante ressaltar que a realização deste estudo ocorreu num período de alta de preços do boi gordo (ANUALPEC, 2011), caracterizando um cenário favorável para a terminação em confinamento. Deve-se considerar, no entanto, que o custo obtido por arroba produzida pode inviabilizar economicamente os benefícios diretos desta atividade em cenários desfavoráveis, apesar de que, o custo de produção em confinamento poder variar de região para região e, em função das peculiaridades de cada sistema. Nesse sentido, menores custos podem ser obtidos por sistemas de produção localizados próximos de regiões produtoras de grãos e fornecedoras de insumos, reduzindo os custos com esses itens pelas menores 
despesas com frete e/ou pela compra em escala. Além disso, a compra de alimentos em momentos de baixa de preço (safra) pode beneficiar a redução do custo com alimentação. Todavia, Lopes et al. (2011) ressaltaram que o confinamento, como atividade exclusiva, apenas será benéfico em situações particulares, como no caso de frigoríficos que se encontram em regiões onde a seca prolongada acarreta grandes dificuldades para a obtenção de animais com grau de acabamento adequado ou, quando os preços de venda da arroba estiverem elevados, se comparados aos custos com alimentação e aquisição de animais. Além disso, esses autores mencionaram que apesar de não ser tão marcante quanto no passado, a variação de preço da arroba na safra e entressafra, em alguns anos, pode permitir o confinamento como uma atividade exclusiva e lucrativa.

Outro aspecto importante a ser considerado sobre o custo de produção obtido foi o elevado preço de comercialização do boi magro, o que de certa forma reflete o período de alta de preço e a baixa oferta de animais no mercado. Segundo Fernandes et al. (2007) o custo de aquisição de animais é um dos principais fatores que determinam a lucratividade no confinamento. Nesse sentido, é importante ressaltar que propriedades que utilizam o confinamento de forma integrada ao sistema de ciclo completo ou recria podem reduzir este custo pelas menores despesas com comissões e fretes, bem como estão menos sujeitos a especulações de mercado. Ressalta-se que o produtor pode evitar a especulação por meio de contratos futuros de compra e venda, tal como os contratos futuros na $\mathrm{BM} \& \mathrm{~F}$ e contratos de boi a termo com a indústria. Além disso, deve-se considerar os aspectos relacionados com o tipo animal, a categoria, o peso inicial e as interações com o plano nutricional, visto que podem determinar variações sobre a conversão alimentar, o período de alimentação e os custos de produção (RESTLE et al., 2001; FERREIRA; SILVA; REIS, 2004; RESTLE et al., 2007; SILVA et al., 2012). Corroborando, Ferreira,
Silva e Reis (2004) ressaltaram que menores custos e, por consequência, maiores margens de lucro são obtidas para grupos genéticos que entram em confinamento mais pesados e permanecem menor tempo confinados.

Considerando a necessidade de reduzir custos para melhorar a margem de lucro, a tomada de decisões pode ser baseada na participação dos custos frente ao custo total, o que neste estudo pode ser verificado na Tabela 8 . Nesse sentido, verificou-se que a participação dos custos fixos frente ao custo total não foi alterada $(\mathrm{P}>0,05)$ pelo aumento do nível de substituição do grão de milho pelo de milheto na dieta, representando em média $1,04 \%$. Deve-se destacar que entre os custos fixos o item mais importante foi o custo com depreciação, representando $0,94 \%$ do custo total. Os valores verificados para o custo com depreciação foram inferiores aqueles apresentados por Missio et al. (2009), os quais verificaram valores de 25,57; 21,73; 17,32 e 15,45\% do custo total para dietas com 22, 40, 59 e $79 \%$ de concentrado na dieta, respectivamente. Em contrapartida, os resultados do presente estudo foram similares aos obtidos por Lopes et al. (2011), os quais verificaram que os custos com depreciação das instalações apresentaram baixa representatividade frente ao custo total $(1,78 \%)$, o que foi atribuído pelos autores ao investimento necessário para as instalações (piso de terra compactado, divisórias em arame liso, cocho do tipo vinilona e sem cobertura). Deve-se considerar que os custos com depreciação estão associados ao tipo de instalações e equipamentos utilizados. Além disso, segundo Rodrigues Filho et al. (2002), os custos com depreciação, bem como aqueles referentes aos juros sobre o capital empatado estão relacionados com o nível nutricional do sistema de terminação. Esses autores mencionaram que planos nutricionais mais elevados determinam custo com depreciação e juros com o capital empatado mais reduzido, enquanto os custos variáveis são maiores, sendo a decisão sobre a maior ou menor taxa de ganho de peso condicionada à melhor relação custo-benefício. 
Tabela 8. Variáveis referentes à composição do custo de produção da terminação de bovinos alimentados com dietas contendo milheto em substituição ao do milho em confinamento.

\begin{tabular}{|c|c|c|c|c|c|c|c|}
\hline \multirow{2}{*}{ Itens ( $\%$ do custo total) } & \multicolumn{4}{|c|}{ Milheto (\%) } & \multirow{2}{*}{$\mathrm{CV}$} & \multicolumn{2}{|c|}{ ER } \\
\hline & 0 & 33 & 66 & 100 & & $\mathrm{~L}$ & Q \\
\hline Custos fixos & 1,03 & 1,03 & 1,04 & 1,07 & 4,72 & 0,142 & 0,762 \\
\hline Oportunidade da terra & 0,09 & 0,08 & 0,09 & 0,09 & 8,53 & 0,996 & 0,984 \\
\hline Depreciações & 0,93 & 0,94 & 0,94 & 0,97 & 5,58 & 0,276 & 0,774 \\
\hline Oportunidade capital depreciado & 0,01 & 0,01 & 0,01 & 0,01 & 5,16 & 0,328 & 0,999 \\
\hline Custos variáveis & 98,97 & 98,97 & 98,96 & 98,93 & 1,76 & $<0,001$ & 0,688 \\
\hline Aquisição de animais ${ }^{1}$ & 70,65 & 72,98 & 73,25 & 75,29 & 1,60 & $<0,001$ & 0,811 \\
\hline Volumoso & 1,87 & 1,79 & 1,96 & 1,91 & 6,32 & 0,306 & 0,911 \\
\hline Concentrado $^{2}$ & 20,68 & 18,39 & 17,93 & 15,85 & 6,48 & 0,002 & 0,852 \\
\hline Alimentação ${ }^{3}$ & 22,54 & 20,18 & 19,89 & 17,76 & 6,46 & 0,003 & 0,863 \\
\hline Mão-de-obra & 1,06 & 1,07 & 1,07 & 1,10 & 5,54 & 0,277 & 0,802 \\
\hline Assistência técnica & 0,67 & 0,68 & 0,68 & 0,70 & 5,67 & 0,283 & 0,796 \\
\hline Controle sanitário & 0,48 & 0,49 & 0,49 & 0,51 & 5,44 & 0,231 & 0,709 \\
\hline Outros & 2,39 & 2,39 & 2,38 & 2,38 & 1,23 & 0,529 & 0,651 \\
\hline Oportunidade capital investido & 1,18 & 1,18 & 1,18 & 1,18 & 0,79 & 0,251 & 0,953 \\
\hline
\end{tabular}

${ }^{1} \mathrm{Y}=70,965+0,042 \mathrm{x}, \mathrm{R}^{2}=0,70, \mathrm{DR}=0,185 ;{ }^{2} \mathrm{Y}=20,041-0,045 ; \mathrm{R}^{2}=0,73, \mathrm{DR}=0,182 ;{ }^{3} \mathrm{Y}=22,235-0,044 \mathrm{x}, \mathrm{R}^{2}=0,68, \mathrm{DR}=$ 0,$361 ; \mathrm{x}=\%$ de milheto na dieta; $\mathrm{A}=$ custo com aquisição dos animais; $\mathrm{DR}=$ probabilidade para os desvios da regressão (ajuste da regressão); $\mathrm{COE}=$ custo operacional efetivo; $\mathrm{COT}=$ custo operacional total.

Fonte: Elaboração dos autores.

O somatório dos custos variáveis, expresso em relação ao custo total, não foi alterado pelo nível de milheto na dieta (Tabela 8). Dentre os custos variáveis, apenas a participação do custo com aquisição dos animais, custo com concentrado e alimentação foram alterados pelo nível de milheto na dieta. $\mathrm{O}$ custo com aquisição dos animais, nesse sentido, aumentou linearmente $(\mathrm{P}<0,05)$, fato associado à redução do custo total com o aumento do nível de milheto nas dietas. Por outro lado, em função do menor custo do milheto em relação ao milho, o custo com concentrado e custo com alimentação reduziram linearmente $(\mathrm{P}<0,05)$ sua participação frente ao custo total. É importante mencionar que os custos variáveis foram os principais componentes do custo de produção, representando em média 98,93\%. Estes resultados suportam a hipótese que os maiores impactos para a redução do custo de produção podem ser obtidos com a redução dos custos variáveis, especialmente aqueles relacionados com a aquisição de animais $(73,04 \%)$ e com concentrado (18,21\%) uma vez que foram os custos individuais com maior representação frente ao custo total.
Os resultados obtidos no presente estudo foram coerentes com aqueles encontrados por Pacheco et al. (2006), os quais avaliando a terminação de novilhos jovens e superjovens de diferentes grupos genéticos em confinamento, verificaram que, em ordem decrescente, o custo com aquisição de animais e o custo com concentrado foram os principais componentes do custo total, sendo que quando desconsiderado o valor de compra dos animais, a alimentação (concentrado + volumosos) foi o item mais representativo frente ao custo total. Por outro lado, Restle et al. (2007) avaliando diferentes pesos de abate em novilhos confinados verificaram que a medida que aumentou o tempo necessário para os animais atingirem o peso de abate, o custo com alimentação passou a superar o custo relativo com aquisição de animais. Da mesma maneira, Missio et al. (2009) avaliando diferentes níveis de concentrado para terminação de tourinhos superjovens em confinamento verificaram que a medida que se elevou o teor de concentrado na dieta, o custo com alimentação passou a ser mais oneroso que o custo com aquisição dos animais. Corroborando, Rodrigues Filho et al. (2002) verificaram que, 
em ordem de importância, a alimentação, o preço do bezerro, a mão-de-obra, outros custos (juro, reparos e depreciação) e os insumos veterinários apresentaram maior participação frente ao custo total. Considerando o exposto, ficou evidente que a participação relativa dos principais custos que oneram a terminação em confinamento (custo com animal e alimentação) está diretamente associada com o tipo de animal e com o aporte nutricional. Nesse sentido, quando ocorre a associação entre animais pesados ao início do confinamento e planos nutricionais baixos ou moderados, o custo com aquisição de animais tende a ser mais representativo frente ao custo total. Todavia, em situações em que são utilizados níveis nutricionais elevados e animais leves ao início do confinamento e/ou pesos de abates elevados, o custo com alimentação tende apresentar maior representatividade frente ao custo total. Nesses casos, torna-se importante o uso de volumosos de melhor qualidade, visando substituir parte dos nutrientes fornecidos pelo concentrado, reduzindo o custo total da dieta, tal como abordado por Pacheco et al. (2006).

A margem bruta, a margem líquida e o lucro aumentaram $\mathrm{R} \$ 0,668 ; 0,675$ e 0,675 para cada ponto percentual a mais de milheto em substituição ao milho da dieta, respectivamente (Tabela 9). Esses resultados discordaram dos obtidos por Rodrigues Filho et al. (2002), os quais verificaram lucro negativo para a terminação de vitelos alimentados com dietas contendo diferentes proporções de concentrado (50 e 75\%) e duas proporções de cama de frango (15 e 22,5\%) em substituição ao concentrado padrão (a base de fubá milho - 86,64\%), fato atribuído ao elevado custo com alimentação e ao preço de comercialização dos bezerros ao abate. Esses autores evidenciaram a necessidade de preço de comercialização diferenciado para esta categoria animal, em que a simulação do preço de comercialização de $0,5,10,15$ e $20 \%$ superior ao preço do boi gordo demonstrou a obtenção de valores positivos a partir do preço de comercialização de $10 \%$ acima do preço do boi gordo para todas as dietas. Missio et al. (2009) verificaram redução linear na receita líquida de $\mathrm{R} \$ 2,49$ para cada ponto percentual de incremento no nível de concentrado da dieta (22 a 79\%). Esses autores simularam a variação dos custos com concentrado em percentagem do preço do $\mathrm{kg}$ do boi gordo $(20,26,36$ e 53\%) e verificaram redução linear da renda líquida com o aumento do concentrado na dieta, sendo que nos maiores níveis de concentrado, a terminação de tourinhos superjovens foi inviabilizada economicamente quando o preço do concentrado atingiu cerca $26 \%$ do preço do boi pronto para abate e, quando o preço do concentrado representou 53\% do valor do preço do boi pronto para abate, todos os níveis de concentrado utilizados se tornaram economicamente inviáveis. No presente estudo o preço do concentrado representou, respectivamente, 9,$72 ; 8,89 ; 8,33$ e $6,94 \%$ do preço do boi gordo para as dietas com $0,33,66$ e $100 \%$ de milheto em substituição ao milho, justificando a maior margem de lucro obtida.

Resultados menos destoantes aos do presente estudo foram obtidos por Pacheco et al. (2006) avaliando a terminação de novilhos confinados com diferentes idades e Restle et al. (2007) avaliando diferentes pesos de abate para novilhos terminados em confinamento, os quais verificaram lucros positivos e inversamente proporcionais ao tempo de confinamento. Segundo Lopes et al. (2011) a viabilidade econômica da terminação em confinamento pode apresentar resultados variáveis em função dos custos com alimentação e preços de aquisição e venda dos animais, fato que pode ser contornado pela utilização de animais mais eficientes nutricionalmente. No entanto, segundo Ferreira, Silva e Reis (2004) as respostas econômicas às variações de preços não podem ser atribuídas exclusivamente aos grupos genéticos, uma vez que os itens com maior impacto sobre a margem bruta são o preço de compra dos animais e o de venda da carne. Corroborando, Ezequiel et al. (2006) enfatizaram ainda que o lucro em confinamento depende de diversos fatores que 
iniciam com a escolha do genótipo, categoria animal, peso inicial e do preço pago pelo boi magro, sendo que o planejamento estratégico do confinamento, considerando a melhor época de aquisição dos insumos e o período de compra dos animais é de extrema importância. Esses autores recomendam ainda que todos os fatores devem ser equacionados e controlados para que o resultado final seja satisfatório, de modo que o lucro proporcionado pelo ganho de peso seja maximizado por meio do aumento na eficiência de utilização dos alimentos ou pelo menor preço de aquisição.

Tabela 9. Variáveis referentes aos indicadores de retorno e de risco do investimento referente à terminação de bovinos alimentados com dietas contendo milheto em substituição ao milho em confinamento.

\begin{tabular}{|c|c|c|c|c|c|c|c|}
\hline \multirow{2}{*}{ Itens } & \multicolumn{4}{|c|}{ Milheto (\%) } & \multirow{2}{*}{$\mathrm{CV}$} & \multicolumn{2}{|c|}{ ER } \\
\hline & 0 & 33 & 66 & 100 & & $\mathrm{~L}$ & Q \\
\hline Taxa mínima de atratividade (TMA), $\%$ a.m. & 0,50 & 0,50 & 0,50 & 0,50 & -- & -- & -- \\
\hline \multicolumn{8}{|l|}{ Retorno do investimento } \\
\hline Margem bruta, $\mathrm{R} \$^{1}$ & 479,03 & 469,71 & 509,93 & 539,68 & 12,78 & 0,002 & 0,545 \\
\hline Margem líquida, $\mathrm{R} \$^{2}$ & 462,66 & 453,52 & 493,81 & 524,03 & 13,06 & 0,002 & 0,537 \\
\hline Lucro, $R \$^{3}$ & 448,47 & 439,39 & 479,58 & 509,87 & 13,43 & 0,002 & 0,536 \\
\hline Valor presente líquido (VPL), $\mathrm{R} \$^{4}$ & 421,22 & 409,63 & 444,01 & 454,30 & 13,91 & 0,036 & 0,723 \\
\hline Índice custo benefício $(\mathrm{IBC})^{5}$ & 1,61 & 1,60 & 1,65 & 1,68 & 3,74 & $<0,001$ & 0,499 \\
\hline ROIA, $\%^{6}$ & 12,61 & 12,45 & 13,34 & 13,89 & 8,12 & $<0,001$ & 0,512 \\
\hline \multicolumn{8}{|l|}{ Risco do investimento } \\
\hline Taxa interna de retorno (TIR), $\%$ a.m. ${ }^{7}$ & 7,39 & 7,29 & 7,83 & 8,16 & 8,28 & $<0,001$ & 0,517 \\
\hline
\end{tabular}

O valor presente líquido (VPL), que representa o quanto se recupera do investimento inicial, considerando sua remuneração quando aplicado na taxa mínima de atratividade, bem como o retorno adicional sobre o investimento (SOUZA; CLEMENTE, 2004), aumentou R\$ 0,402 para cada ponto percentual a mais de incremento do nível de milheto em substituição ao milho da dieta (Tabela 9), sendo o VPL médio de R $\$ 432,29$, indicando que o investimento resultou em excedente monetário. Estes resultados foram concordantes aos verificados por Resende Filho, Braga e Rodrigues (2001), os quais avaliando sistemas de terminação em confinamento com épocas distintas de comercialização verificaram VPLs positivos, demonstrando que a engorda intensiva de bovinos é viável economicamente. Esses autores argumentaram que o lucro da valorização das arrobas preexistentes, considerando a entrada dos animais em confinamento com 12 arrobas, é um dos principais componentes do lucro, pois o retorno econômico é maior que aquele obtido a partir das arrobas ganhas em confinamento, mesmo que o lucro obtido para essas seja elevado.

O índice de benefício custo e o retorno adicional sobre o investimento, os quais representam, respectivamente, o retorno para cada $\mathrm{R} \$ 1,00$ investido e o retorno financeiro além da taxa mínima de atratividade (KASSAI et al., 2000; SOUZA; CLEMENTE, 2004), aumentaram linearmente $(\mathrm{P}<0,05)$ com o incremento do nível de substituição do grão de milho pelo de milheto na dieta (Tabela 9). Os valores obtidos no presente estudo superaram aqueles obtidos por Fernandes et al. (2007), que avaliando o desempenho de diferentes categorias 
de bovinos Canchim em confinamento, verificaram taxa de remuneração mensal superior para novilhos inteiros $(6,36 \%)$, seguido pelas novilhas $(6,87 \%)$, as quais superaram os machos castrados $(4,72 \%)$ alimentados com dietas com cana-deaçúcar + concentrado contendo grãos de girassol em substituição ao milho (principalmente). Estes autores mencionaram que as taxas de remuneração mensal superam às principais aplicações disponíveis no mercado financeiro, tal como no presente estudo. Coan et al. (2008) ressaltaram que mesmo que o resultado econômico do confinamento seja semelhante às aplicações financeiras, deve-se optar por sua utilização, uma vez que os benefícios indiretos justificam sua adoção nos sistemas de produção de carne bovina.

A taxa interna de retorno (TIR), a qual representa a taxa que anula o VPL e indica o risco do investimento apresentar menor retorno que a aplicação do capital no mercado financeiro, considerando a taxa mínima de atratividade (KASSAI et al., 2000; SOUZA; CLEMENTE, 2004), aumentou $0,0085 \%$ a cada ponto percentual a mais de milheto em substituição ao milho da dieta (Tabela 9). Esses resultados indicaram que o risco do investimento diminuiu à medida que aumentou a quantidade de milheto na dieta, reflexo da redução do custo total e manutenção do desempenho animal. Coan et al. (2008) ao avaliarem a viabilidade econômica, o desempenho e as características de carcaça de garrotes confinados alimentados com dietas contendo silagem de capins Tanzânia ou Marandu ou silagem milho, verificaram que a TIR foi maior para as dietas com silagem milho (entre 11 e $12 \%$ a.m.), fato associado ao desempenho animal, uma vez que as dietas compostas pelas silagens dos capins apresentaram em média 79,5\% do ganho de peso proporcionado pela silagem milho, mas com custo/arroba produzida 3,94\% superior.

\section{Conclusões}

O milheto de boa qualidade pode substituir totalmente o milho em dietas com elevadas proporções de concentrado para bovinos em confinamento, pois não altera o consumo de alimento e o desempenho animal. Além disso, a utilização do milheto apresentando custo de comercialização menor ou igual a $77,78 \%$ do custo do milho determina redução dos custos de produção e aumenta a margem de lucro.

\section{Referências}

ANUÁRIO DA PECUÁRIA BRASILEIRA ANUALPEC. 18. ed. São Paulo: Instituto FNP, 2011. $378 \mathrm{p}$.

ASSOCIATION OF OFFICIAL ANALYTICAL CHEMISTS - AOAC. Official methods of analysis. 15. ed. Washington: D.C., 1990. 1141 p.

BERGAMASCHINE, A. F.; FREITAS, R. V. L.; VALÉRIO FILHO, W. V.; BASTOS, J. F. P.; MELLO, S. Q. S.; CAMPOS, Z. R. Substituição do milho e farelo de algodão pelo milheto no concentrado da dieta de novilhos em confinamento. Revista Brasileira de Zootecnia, Viçosa, v. 40, n. 1, p. 154-159, 2011.

CAPPELLE, E. R.; VALADARES FILHO, S. C.; SILVA, J. F. C.; CECON, P. R. Estimativas do valor energético a partir de características químicas e bromatológicas dos alimentos. Revista Brasileira de Zootecnia, Viçosa, v. 30, n. 6, p. 1837-1856, 2001.

COAN, R. M.; REIS, R. A.; RESENDE, F. D.; SAMPAIO, R. L.; SCHOCKEN-ITURRINO, R. P.; GARCIA, G. R.; BERCHIELLI, T. T. Viabilidade econômica, desempenho e características de carcaça de garrotes em confinamento alimentados com dietas contendo silagem de capins tanzânia ou marandu ou silagem milho. Revista Brasileira de Zootecnia, Viçosa, v. 37, n. 2, p. 311-318, 2008.

EZEQUIEL, J. M. B.; GALATI, R. L.; MENDES, A. R.; FATURI, C. Desempenho e características de carcaça de bovinos Nelore em confinamento alimentados com bagaço de cana-de-açúcar e diferentes fontes energéticas. Revista Brasileira de Zootecnia, Viçosa, v. 35, n. 5, p. 2050-2057, 2006. 
FATURI, C.; RESTLE, J.; PASCOAL, L. L.; CERDÓTES, L.; RIZZARDO, R. A. G.; FREITAS, A. K. Avaliação econômica de dietas com diferentes níveis de substituição do grão de sorgo por grão de aveia preta para terminação de novilhos em confinamento. Ciência Rural, Santa Maria, v. 33, n. 5, p. 937-942, 2003.

FERNANDES, A. R. M.; SAMPAIO, A. A. M.; HENRIQUE, W.; PERECIN, D.; OLIVEIRA, E. A.; TÚLLIO, R. R. Avaliação econômica e desempenho de machos e fêmeas Canchim em confinamento alimentados com dietas à base de silagem milho e concentrado ou cana-de-açúcar e concentrado contendo grãos de girassol. Revista Brasileira de Zootecnia, Viçosa, v. 36, n. 4, p. 855-864, 2007.

FERREIRA, I. C.; SILVA, M. A.; REIS, R. P. Análise de custos de diferentes grupos genéticos de bovinos de corte terminados em confinamento. Arquivo Brasileiro de Medicina Veterinária e Zootecnia, Belo Horizonte, v. 56, n. 3, p. 385-391, 2004.

GELAYE, S.; TERRIL, T.; AMOAH, E. A.; MILLER, S.; GATES, R. N.; HANNA, W. W. Nutritional value of pearl millet for lactating and growing goats. Journal of Animal Science, Champaign, v. 75, p. 1409-1414, 1997.

GONÇALVES, J. R. S.; PIRES, A. V.; SUSIN, I.; LIMA, L. G.; MENDES, C. Q.; FERREIRA, E. M. Substituição milho pelo milheto em dietas contendo silagem milho ou silagem de capim-elefante na alimentação de bovinos de corte. Revista Brasileira de Zootecnia, Viçosa, v. 39, n. 9, p. 2032-2039, 2010.

HILL, G. M.; HANNA, W. W. Nutritive characteristics of pearl millet grain in beef cattle diets. Journal of Animal Science, Champaign, v. 68, n. 7, p. 2061-2066, 1990.

HILL, G. M.; NEWTON, G. L.; STREETER, M. N.; HANNA, W. W.; UTLEY, P. R.; MATHIS, M. J. Digestibility and utilization of pearl millet diets fed to finishing beef cattle. Journal of Animal Science, Champaign, v. 74, n. 7, p. 1728-1735, 1996.

KASSAI, J. R.; KASSAI, S.; SANTOS, A.; ASSAF NETO, A. Retorno de investimento: abordagem matemática e contábil do lucro empresarial. 2. ed. São Paulo: Editora Atlas, 2000.

LICITRA, G.; HERNANDEZ, T. M.; VAN SOEST, P. J. Standardization of procedures for nitrogen fractionation of ruminant feeds. Animal Feed Science and Technology, Elsevier, v. 57, n. 4, p. 347-358, 1996.

LOPES, L. S.; LADEIRA, M. M.; MACHADO NETO, O. R.; SILVEIRA, A. R. M. C.; REIS, R. P.; CAMPOS, F. R. Viabilidade econômica da terminação de novilhos Nelore e Red Norte em confinamento na região de Lavras-MG. Ciência Agrotécnica, Lavras, v. 35, n. 4, p.
774-780, 2011.

MISSIO, R. L.; BRONDANI, I. B.; FREITAS, L. S.; SACHET, R. H.; SILVA, J. H. S.; RESTLE, J. Desempenho e avaliação econômica da terminação de tourinhos em confinamento alimentados com diferentes níveis de concentrado na dieta. Revista Brasileira de Zootecnia, Viçosa, v. 38, n. 7, p. 1309-1316, 2009.

NATIONAL RESEARCH COUNCIL - NRC. Nutrients requirements of beef cattle. 7. ed. Washington: D.C., 1996. $242 \mathrm{p}$.

NUSSIO, C. M. B.; SANTOS, F. A. P.; PIRES, A. V.; SIMAS, J. M. C.; ZOPOLLATTO, M. Fontes de amido de diferentes degradabilidades e sua substituição por polpa de citrus em dietas para vacas leiteiras. Acta Scientarium, Maringá, v. 24, n. 4, p. 1079-1086, 2002.

PACHECO, P. S.; RESTLE, J.; VAZ, F. N.; FREITAS, A. K.; PADUA, J. T.; NEUMANN, M.; ARBOITTE, M. $Z$. Avaliação econômica da terminação em confinamento de novilhos jovens e superjovens de diferentes grupos genéticos. Revista Brasileira de Zootecnia, Viçosa, MG, v. 35, n. 1, p. 309-320, 2006.

RESENDE FILHO, M.A.; BRAGA, M. J.; RODRIGUES, R. V. Sistemas de terminação em confinamento: perspectivas para dinamização da cadeia produtiva da carne bovina em Minas Gerais. Revista Brasileira de Economia, Rio de Janeiro, v. 55, n. 1, p. 107-131, 2001.

RESTLE, J.; FATURI, C.; ALVES FILHO, D. C.; BRONDANI, I. L.; SILVA, J. H. S.; KUSS, F.; SANTOS, C. V. M.; FERREIRA, J. J. Substituição do grão de sorgo por casca de soja na dieta de novilhos terminados em confinamento. Revista Brasileira de Zootecnia, Viçosa, v. 33, n. 4, p. 1009-1015, 2004.

RESTLE, J.; NEUMANN, M.; ALVES FILHO, D. C.; PASCOAL, L. L.; ROSA, J. R. P.; MENEZES, L. F. G.; PELLEGRINI, L. G. Terminação em confinamento de vacas e novilhas sob dietas com ou sem monensina sódica. Revista Brasileira de Zootecnia, Viçosa, v. 30, n. 6, p. 1801-1812, 2001.

RESTLE, J.; PACHECO, P. S.; COSTA, E. C.; FREITAS, A. K.; VAZ, F. N.; BRONDANI, I. L.; FERNANANDES, J. J. R. Apreciação econômica da terminação em confinamento de novilhos Red Angus superjovens abatidos com diferentes pesos. Revista Brasileira de Zootecnia, Viçosa, v. 36, n. 4, p. 978-986, 2007.

RIBEIRO, C. V. D. M.; PIRES, A. V.; SIMAS, J. M. C.; SANTOS, F. A. P.; SUSIN, I.; OLIVEIRA JUNIOR, R. C. Substituição milho pelo milheto (Pennisetum americanum) na dieta de vacas holandesas em lactação. Revista Brasileira de Zootecnia, Viçosa, v. 33, n. 5, p. 1351-1359, 2004. 
RODRIGUES FILHO, M.; MANCIO, A. B.; GOMES, S. T.; SILVA, F. F.; LANA, R. P.; RODRIGUES, N. E. B.; SOARES, C. A.; VELOSO, C. M. Avaliação econômica do confinamento de novilhos de origem leiteira, alimentados com diferentes níveis de concentrado e de cama de frango. Revista Brasileira de Zootecnia, Viçosa, v. 31, n. 5, p. 2055-2069, 2002.

SANTOS, F. A. P.; MENEZES JUNIOR, M. P.; SIMAS, J. M. C.; PIRES, A. V.; NUSSIO, C. M. B. Processamento milho e sua substituição parcial por polpa de citros peletizada sobre o desempenho, digestibilidade de nutrientes e parâmetros sanguíneos. Acta Scientarium, Maringá, v. 23, n. 4, p. 923-931, 2001.

SILVA, D. J.; QUEIROZ, A. C. Análises de alimentos: métodos químicos e biológicos. 3. ed. Viçosa, MG: Editora UFV, 2002. 235 p.

SILVA, N. R.; FERREIRA, A. C. H.; FATURI, C.; SILVA, G. F.; MISSIO, R. L.; NEIVA, J. N. M.; ARAÚJO, V. L.; ALEXANDRINO, E. Desempenho em confinamento de bovinos de corte, castrados ou não, alimentados com teores crescentes de farelo do mesocarpo de babaçu. Ciência Rural, Santa Maria, v. 42, n. 10, p. 1882-1887, 2012.
SNIFFEN, C. J; O'CONNOR, J. D.; VAN SOEST, P. J.; FOX, D. G.; RUSSEL, J. B. A net carbohydrate and protein system for evaluating cattle diets: II. Carbohydrate and protein availability. Journal of Animal Science, Champaign, v. 70, n. 12, p. 3562-3577, 1992.

SOUZA, A.; CLEMENTE, A. Decisões financeiras e análise de investimentos. 5. ed. São Paulo: Atlas, 2004. $178 \mathrm{p}$.

VALADARES FILHO, S.; CHIZZOTTI, M. L.; AMARAL, H. F.; MAGALHÃES, K. A.; ROCHA JUNIOR, V. R.; CAPELLE, E. R. Tabelas brasileiras de composição de alimentos para bovinos. 2. ed. Viçosa, MG: UFV, 2006. 239 p.

VAN SOEST, P. J. Collaborative study of acid-detergent fiber and lignin. Journal of the Association of Official Analytical Chemists, Pennsylvania, v. 56, p. 781-784, 1973.

VAN SOEST, P. J.; ROBERTSON, J. B.; LEWIS, B. A. Methods for dietary fiber, neutral detergent fiber, and nonstarch polyssacarides in relation to animal nutrition. Journal of Animal Science, Champaign, v. 74, n. 10, p. 3583-3597, 1991.

WEISS, W. P.; CONRAD, H. R.; PIERRE, N. R. St. A theoretically-based model for predicting total digestible nutrient values of forages and concentrates. Animal Feed Science and Technology, Elsevier, v. 39, p. 95-110, 1992. 